\title{
Breaking the fast: Meal patterns and beliefs about healthy eating style are associated with adherence to intermittent fasting diets
}

\author{
Christina Potter ${ }^{\mathrm{a}, *}$, Rebecca L. Griggs ${ }^{\mathrm{a}}$, Jeffrey M. Brunstrom ${ }^{\mathrm{a}, \mathrm{b}}$, Peter J. Rogers ${ }^{\mathrm{a}, \mathrm{b}}$ \\ a Nutrition and Behaviour Unit, School of Psychological Science, University of Bristol, 12a Priory Road, Bristol, BS8 1TU, UK \\ ${ }^{\mathrm{b}}$ National Institute for Health Research Bristol Biomedical Research Centre, University Hospitals Bristol NHS Foundation Trust and University of Bristol, UK
}

\section{A R T I C L E I N F O}

\section{Keywords:}

Calorie restriction

Meal patterns

Snack patterns

Intermittent fasting

Hunger

Dieting

\begin{abstract}
A B S T R A C T
Many believe that eating three meals each day is healthy and that skipping meals can be detrimental. What remains unclear is whether this belief undermines attempts to restrict energy intake by skipping meals. In an online survey, participants $(N=312)$ with experience of intermittent fasting (IF) reported their beliefs about healthy meal and snack frequency, as well as their non-fasting-dasy and fasting-day eating patterns. They also reported their level of concern with fasting-day meal patterns and their concern to generate fullness when selecting foods. Individuals currently following an IF diet (Current-IF dieters) and those who had previously attempted an IF diet but were non-adherent (Former-IF dieters) took part. Former-IF dieters were more likely to believe that it is healthy to eat three meals a day, punctuated by several snacks. On fasting-days, Former-IF dieters were also more likely to eat breakfast, a mid-morning snack, lunch, and a mid-afternoon snack whereas Current-IF dieters tended to save their eating for dinner and a late evening snack. Former-IF dieters were also more likely to be concerned about the negative consequences of missing a meal, to eat in anticipation of future hunger, and to prioritise fullness over taste when selecting foods. These findings reveal how beliefs about a healthy eating style can play an important role in shaping dietary patterns. Interventions aimed at modifying beliefs about healthy meal patterns may promote IF diet adherence.
\end{abstract}

\section{Introduction}

Perceptions of healthy eating behaviour may shape individuals' meal and snack patterns and food choices. 'Breakfast is the most important meal of the day' is a common saying in both lay and medical discourse. Indeed, the National Health Service (NHS, UK) promotes this idea on their website, stating that individuals should consume breakfast upon waking even if they are not hungry (NHS, 2015b). The NHS website (NHS, 2015a) also highlights findings that breakfast skippers tend to have a higher BMI (Ma et al., 2003; Rampersaud, Pereira, Girard, Adams, \& Metzl, 2005) and that children who skip breakfast perform less well in school (Mahoney, Taylor, Kanarek, \& Samuel, 2005). These findings have served as the foundation for the idea that breakfast is important. However, isolating direct causal benefits of breakfast consumption has proved difficult (Adolphus et al., 2017). The association between breakfast skipping and poor academic performance may be explained by other factors, such as an individual's socio-economic circumstance (Rogers, 1997). Although beliefs in the importance of breakfast are pervasive, researchers often question the underlying evidence (Dickie \& Bender, 1982; Lloyd, Rogers, Hedderley, \& Walker, 1996; Rogers, 1997). Indeed, some studies report no difference in the BMI of breakfast eaters and breakfast skippers (Forslund, Lindroos, Sjostrom, \& Lissner, 2002; Walker, Walker, Jones, \& Ncongwane, 1982), and some suggest potential benefits of skipping breakfast (Rogers et al., 2013; Yoshimura, Hatamoto, Yonekura, \& Tanaka, 2017).

Another common belief is that consuming three meals throughout the day is healthy (Assanand, 1996). Again, the evidence supporting this claim is inconclusive. Some studies find that eating frequency is positively associated with obesity and that consuming multiple meals promotes greater daily energy intake (Forslund, Torgerson, Sjöström, \& Lindroos, 2005). Others have found an inverse relationship between meal frequency and body weight (Toschke, Küchenhoff, Koletzko, \& Kries, 2005; Toschke, Thorsteinsdottir, \& von Kries, 2009). Increased meal frequency has also been associated with physiological benefits, such as improved glucose tolerance and hypercholesterolemia (Faíbry \& Tepperman, 1970). In contrast, the physiological benefits of skipping regular meal times (intermittent fasting, IF) are robust and well-

\footnotetext{
* Corresponding author. Nuffield Department of Primary Care Health Sciences, University of Oxford, Radcliffe Observatory Quarter, Woodstock Road, Oxford, OX2 6GG, UK.

E-mail address: Christina.Potter@phc.ox.ac.uk (C. Potter).
} 
documented (Davis et al., 2016; Seimon et al., 2015; Varady \& Hellerstein, 2007). Notwithstanding this conflicting evidence, people are often advised to eat regularly throughout the day and a common belief is that eating regular meals (particularly breakfast) is important and, conversely, skipping meals is unhealthy.

Weight-loss diets that incorporate intermittent food restriction, such as the Every Other Day Diet (Varady \& Gottlieb, 2013) and the 5:2 Fast Diet (Mosley \& Spencer, 2015), are increasingly popular. A common barrier, reported by individuals following a traditional continuous energy restriction (CER) diet, is difficulty adhering to the level of restriction that is prescribed (Varady, 2011). It has been suggested that dieting on intermittent days leads to positive cognitive side effects (e.g. improved mood, increased willpower) both because energy restriction is required only intermittently and because individuals find it easy to comply with a diet that permits 'normal' eating on non-fasting days (Mosley \& Spencer, 2015). Further, IF diets have been associated both with weight loss and a lowered risk of several major health conditions (Heilbronn, Smith, Martin, Anton, \& Ravussin, 2005; Varady \& Hellerstein, 2007).

The primary aim was to understand the characteristics that differentiate individuals who are adherent to (i.e. have not stopped) an IF diet. More specifically, we explored whether underlying beliefs about healthy meal and snack patterns might differentiate people who find it easy to adhere to an IF diet. We hypothesised that individuals who believe it is unhealthy to skip meals or snacks intermittently will be less likely to skip meals or snacks and will be less likely to adhere to an IF diet. We also explored differences between the food choices of CurrentIF and Former-IF Dieters, on both fasting and non-fasting days. In particular, we focused on the extent to which different dieters select foods based on their expected satiation (ability to confer fullness) versus their palatability (pleasurable taste). Many individuals express concern about feeling sufficiently full (Brunstrom et al., 2016) and may prioritise and select foods based on the satiety they are expected to confer (Brunstrom \& Rogers, 2009). We hypothesised that these individuals will be less likely to adhere to an IF diet because they are likely to feel especially deprived on fasting days.

IF diets may also require a shift from a traditional three-meals-a-day pattern of eating and that this might lead to several concerns. Specifically, following an IF diet might lead to feelings of missing out on the pleasure of eating, missing out on eating with family at meal times, or feeling that fasting is otherwise disruptive to an individual's daily schedule. Therefore, an additional aim was to assess whether non-adherence is associated with perceived deprivation or inconvenience on fasting-days. Finally, the belief in a meal-to-meal model of energy balancing may promote eating to avoid perceived adverse effects of future hunger (Rogers, Ferriday, Jebb, \& Brunstrom, 2016). Indeed, individuals might even consume a meal or snack, even in the absence of hunger, to reduce the likelihood of feeling hungry in future. Accordingly, we hypothesised that the tendency to engage in "eating in anticipation of future hunger" would be related to poor IF diet adherence.

\section{Material and methods}

\subsection{Participants}

An online survey was advertised through two sources; i) our laboratory volunteer database, which includes students and staff from the University of Bristol and members of the Bristol (UK) public, and ii) an advertisement on the "5:2 Intermittent Fasting Diet" Facebook page. All participants were aged 18 years or older and were asked to complete the survey in one sitting and without interruption. Participants reported whether they were currently on a diet, and if so which diet. They also indicated whether they had ever followed an IF diet. Using this information, we identified a group of participants who were currently following an IF diet (Current-IF Dieters, $n=205$ ) and a group who had previously tried an IF diet but had now stopped $(n=117)$. A small number of these respondents explicitly identified that they had previously tried an IF diet but stopped because they had reached their target weight $(n=10)$, so these participants were not included in the analyses. The majority of participants who did not adhere to the IF diet (Former-IF Dieters, $n=107$ ) were included in the analyses. No payment was offered for participation. Instead, respondents were voluntarily entered into a prize draw to win one of two shopping vouchers worth $£ 50$ Sterling. Ethical approval was obtained from the University of Bristol's Faculty of Science Human Research Ethics Committee.

\subsection{Questionnaire}

The questionnaire was administered through the Bristol Online Survey Tool (BOS, 2015). Participants began the survey by providing electronic informed consent. The survey included questions eliciting; i) demographic information, ii) current diet status and diet history, iii) beliefs about healthy meal and snack patterns, iv) information about meal and snack patterns on fasting- and non-fasting-days, v) preferences for fullness versus taste on fasting- and non-fasting-days, vi) evidence of eating in the absence of hunger, and vii) concerns with fasting.

\subsection{Participant demographics and diet status}

Participants were asked to report their age, sex, height, and weight. Participants' height and weight was used to calculate their BMI (kg/ $\mathrm{m}^{2}$ ). All reported the duration they had been following their current diet, with response options: "one week or less", "2-4 weeks", "5-8 weeks", "3-6 months", "7-12 months", or "more than a year". These values were recorded for all Current-IF Dieters as well as any Former-IF Dieters who had switched from their IF diet and were currently following another, non-IF diet. Former-IF Dieters were also asked to report the duration of their IF diet. This was captured in a free-text response to the question: "Have you ever followed an intermittent fasting diet? If so, please provide details."

\subsection{Diet history from previous five years}

Participants provided information regarding their diet history for the previous five years. This included the number of attempts at weight loss using each of the following types of weight-loss diet: low-calorie, low-carbohydrate, low-fat, "crash" diet, "detox" diet, and IF diet. Participants reported how successful they felt their dieting had been during this five-year period on a five-point Likert scale from "Not at all successful" to "Extremely successful."

\subsection{Beliefs about healthy meal and snack patterns}

To assess beliefs about healthy meal and snack patterns, two questions from the Personal Theories of Hunger and Eating Questionnaire (PTHE) (Assanand, 1996) were included. The PTHE questionnaire has a reliable scale (Cronbach's $\alpha=0.85$ ), and principal components factor analysis demonstrate the scale accounts for a large total variance (greater than 0.59) in set-point beliefs. Participants were asked to respond to the questions "Three meals eaten at three different times during the day is ... ?" (PTHE \#9) and "Several snacks eaten throughout the day is ... ?" (PTHE \#10) with response options "very unhealthy", "somewhat unhealthy", "neutral", "somewhat healthy", or "very healthy."

\subsection{Meal and snack patterns on fasting-days versus non-fasting-days}

To determine meals and snacks that were routinely consumed on a non-fasting-day, participants were asked "Which of the following meals and snacks do you eat in a typical day?" and were instructed to "Tick all that apply" with response options "breakfast", "mid-morning snack", "lunch", "mid-afternoon snack", "dinner", and "late evening snack." To 
Table 1

Participant characteristics.

\begin{tabular}{|c|c|c|c|}
\hline & Current-IF Dieters $(n=205)$ & Former-IF Dieters $(\mathrm{n}=107)$ & Statistical tests \\
\hline Sex (\% female) & 93.7 & 83.2 & $\chi^{2}(1, N=312)=8.63, p=.003$ \\
\hline Age (years) & $48.5(12.0)$ & $33.6(14.3)$ & $\mathrm{F}_{1,310}=95.08, p<.001, \eta_{p}^{2}=.235$ \\
\hline BMI $(\mathrm{kg} / \mathrm{m} 2)$ & $26.6(4.5)$ & $24.3(4.2)$ & $\mathrm{F}_{1,310}=18.20, p<.001, \eta_{p}^{2}=.055$ \\
\hline$\%$ underweight $\left(<18.5 \mathrm{~kg} / \mathrm{m}^{2}\right)$ & $0.5_{\mathrm{a}}$ & $2.8_{\mathrm{a}}$ & $\chi^{2}(3, N=312)=13.83, p=.003$ \\
\hline$\%$ normal weight $\left(18.5-25 \mathrm{~kg} / \mathrm{m}^{2}\right)$ & $42.4 \mathrm{a}$ & $60.7_{b}$ & \\
\hline$\%$ overweight $\left(25-30 \mathrm{~kg} / \mathrm{m}^{2}\right)$ & $38.0_{\mathrm{a}}$ & $25.2_{\mathrm{b}}$ & \\
\hline$\%$ obese $\left(>30 \mathrm{~kg} / \mathrm{m}^{2}\right)$ & $19.0_{\mathrm{a}}$ & $11.2_{\mathrm{a}}$ & \\
\hline \multicolumn{4}{|c|}{ Duration following an IF diet (\% within group) } \\
\hline One week or less & $2 \mathrm{a}$ & $4.8 \mathrm{a}$ & $\chi^{2}(5, n=288)=77.95, p<.001$ \\
\hline $2-4$ weeks & $8.3_{\mathrm{a}}$ & $39.3_{\mathrm{b}}$ & \\
\hline 5-8 weeks & $7.4_{\mathrm{a}}$ & $13.1_{\mathrm{a}}$ & \\
\hline 3-6 months & $19.1_{\mathrm{a}}$ & $33.3_{\mathrm{b}}$ & \\
\hline 7-12 months & $21.6_{a}$ & $3.6_{\mathrm{b}}$ & \\
\hline more than a year & $41.7 \mathrm{a}$ & $6_{\mathrm{b}}$ & \\
\hline
\end{tabular}

Notes. Values are displayed as means (standard deviations) or percentages within dieter category. Each subscript letter denotes values that do not differ significantly from one another at the $\alpha=0.05$ level.

determine their meal and snack patterns on fasting-days, participants were given the following scenario "If you were only permitted to eat 500 calories (women) or 600 calories (men) throughout the day, which of the following meals and snacks would you eat?" and again asked to "Tick all that apply", with the same meal and snack response options.

\subsection{Prioritisation of satiation over palatability}

An additional aim was to understand whether priorities shift when making food selections on fasting versus non-fasting-days; specifically, whether individuals select foods based on satiation (fullness conferred by consuming the food) or palatability (pleasurable taste). Respondents were asked "On a typical day, which of these would you prioritise if you had to select one option?" and "If you were only permitted to eat 500 calories (women) or 600 calories (men) of food throughout the day, which of these would you prioritise if you had to select one option?". In each case, they selected either "Foods that are tasty" or "Foods that are filling". Responses were coded into one of four categories: (i) a shift from preferring taste on non-fasting-days to preferring fullness on fasting-days (shift to fullness), (ii) a shift from preferring fullness on non-fasting-days to preferring taste on fasting-days (shift to taste), (iii) no shift because fullness was preferred on both non-fasting-days and fasting-days (fullness always preferred), or (iv) no shift because taste was preferred on both non-fasting-days and fasting-days (taste always preferred).

\subsection{Eating in anticipation of future hunger}

A further aim was to explore the relationship between dieter status (Current-IF or Former-IF) and the tendency to eat in anticipation of future hunger. To assess these relationships, participants were asked "How often do you eat a meal or snack when you aren't hungry 'just in case' you might feel hungry or be without food later in the day?" with response options "never", "rarely", "sometimes", "often", or "always."

\subsection{Concerns about fasting meal patterns}

Participants were asked to rate their level of concern about the consequences of IF. They were asked to "Imagine you were only permitted to eat a total of 500 calories (women) or 600 calories (men) over a 24-h period. Which of the following (if any) would be a concern?" Participants then rated their level of concern ("No concern", "slight concern", "some concern", "moderate concern", or "extreme concern") associated with variety of side effects and barriers to fasting. In this study we were interested in responses that relate directly to patterns of eating; "Feelings of 'missing out' on eating at habitual meal and snack times", "Eating this way would be disruptive to my daily life and schedule", and
"Difficulty not eating when preparing meals for others."

\subsection{Data analysis}

ANOVA was used to explore differences in the age and BMI of Current-IF and Former-IF Dieters. Chi-square was used to assess differences in sex, the duration of the IF diet, previous diet attempts during past five years, and perceived diet success. ANOVA was used to assess differences between Current- and Former-IF Dieters in their preferred meal and snack patterns, shift in preference for fullness versus taste, and eating in anticipation of future hunger. Chi-square analyses tested for differences in concerns about fasting, beliefs about healthy eating style (PTHE \#9 and \#10), and non-fasting-day prioritisation of fullness versus taste. To account for multiple comparisons, significance values have been adjusted using the Bonferroni correction method.

\section{Results}

\subsection{Participant characteristics}

Both groups were predominantly female; however, there was a higher proportion of female respondents in the Current-IF dieter sample. Current-IF Dieters were also significantly older and had a higher BMI than Former-IF Dieters. The majority of the Current-IF Dieters $(n=197)$ followed the 5:2 Fasting Diet, with the remaining $(n=8)$ following other intermittent fasting diets (e.g., 4:3 diet, the Every Other Day Diet). Current-IF Dieters followed an IF diet for a longer duration than Former-IF Dieters $(p<.001)$, although several Former-IF Dieters $(n=24)$ did not provide information regarding the duration that they followed an IF diet. The majority of Former-IF Dieters $(n=84)$ reported that they no longer follow any diet for weight loss. The remaining Former-IF Dieters who continued to diet reported following calorie-controlled diets $(n=7)$, low-carbohydrate diets $(n=3)$ or other methods for weight loss, such as "juicing", "eating healthy", "no processed foods" $(n=13)$. See Table 1 for associated analyses, together with summary statistics for both groups of dieters.

The Former-IF Dieters reported attempting more diets for weight loss during the previous five years compared with Current-IF Dieters $\left(\chi^{2}(10, N=312)=18.84, p=.042\right)$, see Table 2 . However, there were no group differences in perceived weight-loss success during the previous five years. Both groups also showed similar diet histories across all weight loss diet types, with the only exception being that Former-IF Dieters were more likely to have had previous experience attempting an IF diet in the past five years than Current-IF Dieters $(p<.05)$ (see Table 3 ). 
Table 2

Weight loss diet attempts during previous five years.

\begin{tabular}{|c|c|c|c|c|c|c|c|c|c|c|c|}
\hline \multicolumn{12}{|c|}{ Number of weight loss diet attempts } \\
\hline & 0 & 1 & 2 & 3 & 4 & 5 & 6 & 7 & 8 & 9 & $10+$ \\
\hline Current-IF Dieters & $3.4 \mathrm{a}$ & $24.4_{b}$ & 24.9 a & $17.6 \mathrm{a}$ & $4.9 \mathrm{a}$ & $9.3_{\mathrm{a}}$ & $3.9 \mathrm{a}$ & $1.0_{\mathrm{a}}$ & $1.5_{\mathrm{a}}$ & $0.0_{\mathrm{a}}$ & $9.3 \mathrm{a}$ \\
\hline Former-IF Dieters & $8.4_{a}$ & $14.0_{\mathrm{a}}$ & $24.3_{\mathrm{a}}$ & $10.3_{\mathrm{a}}$ & $4.7 \mathrm{a}$ & $13.1_{\mathrm{a}}$ & $1.9_{\mathrm{a}}$ & $1.9 \mathrm{a}$ & $1.9_{\mathrm{a}}$ & $0.9_{\mathrm{a}}$ & $18.7_{b}$ \\
\hline
\end{tabular}

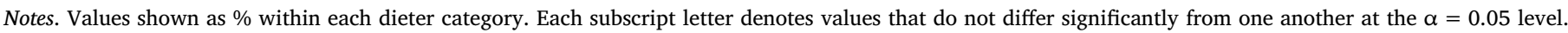

\subsection{Beliefs about healthy meal and snack patterns}

Former-IF Dieters were more likely to believe that eating three different meals at separate times throughout the day is healthy (PTHE \#9) than did Current-IF Dieters. Additionally, Former-IF Dieters were more likely to believe that several snacks eaten throughout the day is healthy (PTHE \#10) than did Current-IF Dieters (see Table 4).

\subsection{Meal and snack patterns on fasting- and non-fasting-days}

On non-fasting-days, both dieter groups reported similar meal and snack patterns, with the only apparent difference being in the snacking behaviour of Former-IF Dieters. Former-IF Dieters were more likely to report eating a mid-morning snack $(44.9 \%$ vs. $15.6 \%)\left(\chi^{2}(1\right.$, $N=312)=31.55, p<.001)$ and a mid-afternoon snack $(49.5 \%$ vs. $37.6 \%)\left(\chi^{2}(1, N=312)=4.15, p=.042\right)$ compared with Current-IF Dieters (see Fig. 1, Panel A). However, on fasting-days there were significant differences between groups on all eating occasions. On fastingdays Former-IF Dieters were more likely to report that they would eat breakfast $(32.7 \%$ vs. $17.1 \%)\left(\chi^{2}(1, N=312)=9.88, p<.05\right)$, a midmorning snack $(16.8 \%$ vs. $3.9 \%)\left(\chi^{2}(1, N=312)=15.36, p<.001\right)$, lunch $(48.6 \%$ vs. $29.8 \%)\left(\chi^{2}(1, N=312)=10.81, p=.001\right)$, and a mid-afternoon snack $(16.8 \%$ vs. $8.8 \%)\left(\chi^{2}(1, \quad N=312)=4.46\right.$, $p<.05$ ) (see Fig. 1, Panel B). Current-IF Dieters showed a preference for saving their eating until later in the day, with a larger percentage choosing to eat dinner $(96.6 \%$ vs. $83.2 \%)\left(\chi^{2}(1, N=312)=17.15\right.$, $p<.001)$ and a late-evening snack $(13.2 \%$ vs. $3.7 \%)\left(\chi^{2} \quad(1\right.$, $N=312)=6.99, p<.05$ ).

\subsection{Preference for fullness versus taste on fasting and non-fasting-days}

Table 2 shows dieters' preference for fullness versus taste on nonfasting-days and their shift in preference, if applicable, on fasting-days. On non-fasting-days, most prioritised foods based on taste rather than fullness. Current IF Dieters were even more likely to do so, however the difference between groups narrowly missed significance $(p=.053)$. On fasting-days, approximately half of Current-IF Dieters and Former-IF Dieters changed their priorities when making food selections and shifted their preference from taste to fullness (shift to fullness). Across both groups, there was minimal observed shift ( $2 \%$ of Current-IF Dieters) from prioritising fullness on non-fasting-days to prioritising taste on fasting-days (shift to taste). A higher proportion of Former-IF Dieters always prioritised fullness (fullness always preferred) than did Current-IF Dieters, and Current-IF Dieters were more likely to prioritise taste on both non-fasting- and fasting-days (taste always preferred) compared to Former-IF Dieters.

\subsection{Eating in anticipation of future hunger}

Compared with Current-IF Dieters, Former-IF Dieters were more likely to report eating when they did not feel hungry "just in case" they might be hungry later $\left(\mathrm{F}_{1,312}=5.04, p=.026, \eta^{2} \mathrm{p}=.016\right)$.

\subsection{Concerns about fasting-day meal patterns}

Table 2 shows participants' average level of concern for each potential barrier to fasting, with higher values indicating a higher level of concern. Compared to Current-IF Dieters, Former-IF Dieters reported significantly more concern that restricting their calorie intake to $500 \mathrm{kcal}$ (women) or $600 \mathrm{kcal}$ (men), indicating that it would; i) be disruptive to their daily schedule $(p<.001)$, ii) promote feelings of "missing out" at habitual meal and snack times $(p<.001)$, and iii) produce "difficulty not eating when preparing meals for others" $(p=.002)$.

\section{Discussion}

Together, these findings indicate that beliefs about a healthy eating style may affect people's perceived ability to restrict calorie intake in an intermittent fasting diet. Specifically, participants who believed skipping meals to be unhealthy were more likely to indicate that they would eat several meals a day, even on fasting-days. Current-IF Dieters were more likely to reserve their eating to dinner or a late evening snack on

Table 3

Perceived dieting success and number of weight loss diet attempts during previous five years.

\begin{tabular}{|c|c|c|c|}
\hline & Current-IF Dieters $(\mathrm{n}=205)$ & Former-IF Dieters $(n=107)$ & Statistical tests \\
\hline \multicolumn{4}{|c|}{ "How successful would you say that your dieting has been in the past five years?" } \\
\hline Not applicable & 3.4 & 6.5 & \multirow[t]{6}{*}{$\chi^{2}(5)=5.592, p=.348$} \\
\hline Not at all successful & 9.3 & 6.5 & \\
\hline A little successful & 28.3 & 21.5 & \\
\hline Somewhat successful & 22.0 & 23.4 & \\
\hline Moderately successful & 19.5 & 27.1 & \\
\hline Extremely successful & 17.6 & 15.0 & \\
\hline \multicolumn{4}{|c|}{ "During the past 5 years, which of the following types of diet for weight loss have you tried?" } \\
\hline Low-calorie diets (e.g. Weight Watchers, Nutrisystem, Slim-Fast) & 42.9 & 35.5 & \multirow{7}{*}{$\begin{array}{l}\chi^{2}(1)=1.605, p=.205 \\
\chi^{2}(1)=0.148, p=.701 \\
\chi^{2}(1)=2.018, p=.155 \\
\chi^{2}(1)=2.846, p=.092 \\
\chi^{2}(1)=3.367, p=.067 \\
\chi^{2}(1)=7.327, p=.007 \\
\chi^{2}(1)=0.571, p=.450\end{array}$} \\
\hline Low-carbohydrate diets (e.g. Atkins, Dukan, South Beach diet) & 21.5 & 23.4 & \\
\hline Low-fat (e.g. McDougalls) & 5.9 & 10.3 & \\
\hline Crash diets (e.g. Cabbage soup diet, Grapefruit diet, Subway diet) & 5.9 & 11.2 & \\
\hline Detox diets (e.g. Juice cleansing, Master cleanse) & 6.8 & 13.1 & \\
\hline Intermittent fasting diets (e.g. The 5:2 Diet, The 2-Day Diet) & 81.0 & 92.5 & \\
\hline Other (e.g. Jenny Craig, Mediterranean, Paleo Diet, Slimming World) & 27.3 & 23.4 & \\
\hline
\end{tabular}

Notes. Values shown as \% within each dieter category. Values for "type of weight loss diet tried" are displayed as the percentage within each dieter group that responded "Yes" for each. For all analyses, $N=312$. 
Table 4

Beliefs about healthy eating patterns, preference for fullness versus taste, concerns with fasting-day meal patterns, and tendency to eat in anticipation of future hunger between Current-IF and Former-IF Dieters.

\begin{tabular}{|c|c|c|c|}
\hline & $\begin{array}{l}\text { Current-IF } \\
\text { Dieters } \\
(\mathrm{n}=205)\end{array}$ & $\begin{array}{l}\text { Former-IF } \\
\text { Dieters } \\
(n=107)\end{array}$ & Statistical tests \\
\hline \multicolumn{4}{|c|}{ PTHE \#9 "Three meals eaten at three times throughout the day is ..." } \\
\hline Very unhealthy & $0.5_{\mathrm{a}}$ & $0.9 \mathrm{a}$ & $\chi^{2}(4, N=312)=18.73$ \\
\hline $\begin{array}{l}\text { Somewhat } \\
\text { unhealthy }\end{array}$ & $2.9 \mathrm{a}$ & $2.8 \mathrm{a}$ & $p<.001$ \\
\hline Neutral & $45.9 \mathrm{a}$ & $22.4_{\mathrm{b}}$ & \\
\hline $\begin{array}{c}\text { Somewhat } \\
\text { healthy }\end{array}$ & $38.5_{a}$ & $49.5_{a}$ & \\
\hline Very healthy & $12.2 \mathrm{a}$ & $24.3_{\mathrm{b}}$ & \\
\hline \multicolumn{4}{|c|}{ PTHE \#10 "Three meals eaten at three times throughout the day is ... " } \\
\hline Very unhealthy & $11.2 \mathrm{a}$ & $10.3_{\mathrm{a}}$ & $\chi^{2}(4, N=312)=23.91$, \\
\hline $\begin{array}{l}\text { Somewhat } \\
\text { unhealthy }\end{array}$ & $40.5 \mathrm{a}$ & $27.1_{\mathrm{b}}$ & $\mathrm{p}<.001$ \\
\hline Neutral & $34.1_{\mathrm{a}}$ & 29 a & \\
\hline $\begin{array}{c}\text { Somewhat } \\
\text { healthy }\end{array}$ & $14.1_{\mathrm{a}}$ & $27.1_{\mathrm{b}}$ & \\
\hline Very healthy & $0_{\mathrm{a}}$ & $6.5_{\mathrm{b}}$ & \\
\hline \multicolumn{4}{|c|}{ Fullness vs taste on non-fasting-days (\% within group) } \\
\hline $\begin{array}{l}\text { Fullness } \\
\text { preferred }\end{array}$ & $23.4_{a}$ & $33.6_{\mathrm{a}}$ & $\begin{array}{l}\chi^{2}(1, N=312)=3.74 \\
p=.053\end{array}$ \\
\hline Taste preferred & $76.6_{a}$ & $66.4 \mathrm{a}$ & \\
\hline \multicolumn{4}{|c|}{ Shift in preference for fullness vs taste (non-fasting-day to fasting-day) } \\
\hline $\begin{array}{l}\text { "Shift to } \\
\text { fullness" }\end{array}$ & $49.3_{\mathrm{a}}$ & $50.5_{\mathrm{a}}$ & $\begin{array}{l}\chi^{2}(3, N=312)=10.10 \\
p=.018\end{array}$ \\
\hline "Shift to taste" & $2.0_{\mathrm{a}}$ & $0_{\mathrm{a}}$ & \\
\hline $\begin{array}{l}\text { "Fullness always } \\
\text { preferred" }\end{array}$ & $21.5 \mathrm{a}$ & $33.6_{\mathrm{b}}$ & \\
\hline $\begin{array}{l}\text { "Taste always } \\
\text { preferred" }\end{array}$ & $27.3 \mathrm{a}$ & $15.9 \mathrm{~b}$ & \\
\hline \multicolumn{4}{|c|}{ Concerns with fasting-day meal patterns } \\
\hline \multicolumn{4}{|c|}{ Disruptive to daily life and schedule } \\
\hline No concern & $66.8 \mathrm{a}$ & $33.6_{\mathrm{b}}$ & $\chi^{2}(4, N=312)=50.59$ \\
\hline Slight concern & $23.4 \mathrm{a}$ & $26.2 \mathrm{a}$ & $p<.001$ \\
\hline Some concern & $3.4_{\mathrm{a}}$ & $16.8_{\mathrm{b}}$ & \\
\hline $\begin{array}{r}\text { Moderate } \\
\text { concern }\end{array}$ & $5.4_{a}$ & $12.1_{\mathrm{b}}$ & \\
\hline Extreme concern & $1.0_{\mathrm{a}}$ & $11.2_{\mathrm{b}}$ & \\
\hline \multicolumn{4}{|c|}{ Feelings of "missing out" at meal and snack times } \\
\hline No concern & $52.7 \mathrm{a}$ & $27.1_{\mathrm{b}}$ & $\chi^{2}(4, N=312)=47.82$ \\
\hline Slight concern & $33.7_{\mathrm{a}}$ & $24.3_{\mathrm{a}}$ & $p<.001$ \\
\hline Some concern & $8.3_{\mathrm{a}}$ & $22.4_{\mathrm{b}}$ & \\
\hline $\begin{array}{r}\text { Moderate } \\
\text { concern }\end{array}$ & $2.9 \mathrm{a}$ & $16.8_{\mathrm{b}}$ & \\
\hline Extreme concern & $2.4_{\mathrm{a}}$ & $9.3_{\mathrm{b}}$ & \\
\hline \multicolumn{4}{|c|}{ Difficulty not eating when cooking for others } \\
\hline No concern & $49.3_{\mathrm{a}}$ & $31.8_{\mathrm{b}}$ & $\chi^{2}(4, N=312)=17.01$ \\
\hline Slight concern & $19.5_{\mathrm{a}}$ & $23.4 \mathrm{a}$ & $p=.002$ \\
\hline Some concern & $17.1_{\mathrm{a}}$ & $13.1_{\mathrm{a}}$ & \\
\hline $\begin{array}{r}\text { Moderate } \\
\text { concern }\end{array}$ & $8.3_{\mathrm{a}}$ & $18.7 \mathrm{~b}$ & \\
\hline Extreme concern & $5.9_{\mathrm{a}}$ & $13.1_{\mathrm{b}}$ & \\
\hline
\end{tabular}

Notes. All values are shown as percentages within dieter category or as means (standard deviations). Each superscript letter denotes values that do not differ significantly from one another at the $\alpha=0.05$ level.

fasting days, suggesting that this approach aids diet adherence. It may be the case that breaking the fast early in the day (i.e., eating breakfast) makes it more difficult for an individual to refrain from eating again, in other words, promotes disinhibition (Rogers \& Brunstrom, 2016). Delaying eating occasions until the end of the day has the advantage that an individual can avoid contact with food in the morning and early afternoon. This might serve as a simple strategy to reduce the need for calorie-counting as well as reducing opportunities for reminders about eating and encounters with food-related stimuli throughout the day (one just gets on with other responsibilities). Of course, when avoiding meals, the pleasure of eating is missed (Rogers \& Brunstrom, 2016), but physical and cognitive performance is likely to be unaffected (Rogers \& Brunstrom, 2016; Rogers et al., 2016). Additionally, people may find fullness comforting because they fear an empty stomach, which is equated with hunger. However, fullness itself does not appear to be intrinsically rewarding (Sclafani \& Ackroff, 2004), arguably because fullness prevents further energy intake (Rogers \& Brunstrom, 2016). Regardless of whether individuals prioritise pleasure of eating or fullness, they risk feeling deprived on fasting days, due to diminished pleasure from eating, or lack of fullness, or both.

Additionally, individuals who are concerned about hunger may be more likely to eat in order to prevent future hunger, even if they are not currently feeling a desire to eat. Our findings suggest that asking prospective dieters about the biological origin of their own hunger might help to inform appropriate guidance - those that express fewer concerns about hunger might be particularly encouraged to adopt an IF diet (Rogers \& Brunstrom, 2016; Rogers et al., 2016). One possibility is that IF dieters might be encouraged to select low-energy-dense foods on fasting-days, because these can be consumed in larger quantities and promote feelings of fullness. Indeed, when only small portions are available, individuals tend to select the foods that promote maximum fullness (Brunstrom et al., 2016). By contrast, our findings suggest that this advice may not be helpful. Specifically, nearly one-third of those who adhered to the IF diet (Current-IF dieters) reported a preference for taste over fullness when selecting foods on both fasting and non-fastingdays. It may be that these individuals were simply less concerned with feelings of fullness prior to starting their IF diet. Alternatively, it could be that extended experience with IF modified beliefs about hunger and healthy eating patterns. Flavoursome foods, although likely to be more energy-dense and thus selected in smaller portions on fasting days, may leave individuals feeling more satisfied and may promote IF diet adherence (Rogers et al., 2016).

It remains unclear why the two dieter groups differed in their beliefs about healthy eating (main meals and snacks) and in their concerns with fasting. A limitation to the current study is that baseline beliefs (pre-IF diet experience) were not assessed, so it is difficult to determine whether beliefs about healthy eating style affected the experience of IF or whether a period of IF caused these beliefs to be modified. Future studies could assess whether initial beliefs and preconceptions about IF can be modified to improve IF adherence. An additional limitation is that Former-IF dieters were not asked to report their reasons for quitting their IF diet, so the observed relationships between diet adherence and meal patterns may be due to other side effects of fasting that were not assessed. A further concern is that the two samples were not equally matched demographically. The Current-IF Dieters had a higher proportion of females $(93.7 \%$ versus $83.2 \%)$ and a higher average BMI ( 26.6 versus $24.3 \mathrm{~kg} / \mathrm{m}^{2}$ ) than the Former-IF Dieters. There was also a difference in age between the Current-IF and Former-IF Dieters (48.5 versus 33.6 years, respectively). Age (experience) may affect beliefs about healthy eating behaviour or overall willingness to adhere to an IF diet, and might help to explain some of the relationships described in this study. Future studies should consider the extent to which age influences beliefs about healthy eating and willingness to adhere to IF diets.

Notably, differences in beliefs and preferences between dieter groups assessed in this study may also apply to dieting for weight loss generally. For example, when asked about their dieting history during the previous five years, both groups reported similar perceived levels of success. However, the Former-IF dieters were more likely to have attempted 10 or more weight loss diets during that time. It may be the case that preferences for taste versus fullness, preferences for snacking, or concerns about future hunger also relate to adherence to weight loss diets in general and are not specific to IF diets. We also note that several of the survey questions were not validated but were of particular interest nonetheless. Further, we note that these results might only reflect individuals who are similar to the study sample, and might not extend to other groups such as those who are growing (children and adolescents), athletes, or individuals with diabetes. Also, participants did not provide information about physical activity, and high levels might 
A.

Non-fasting-day meal and snack patterns

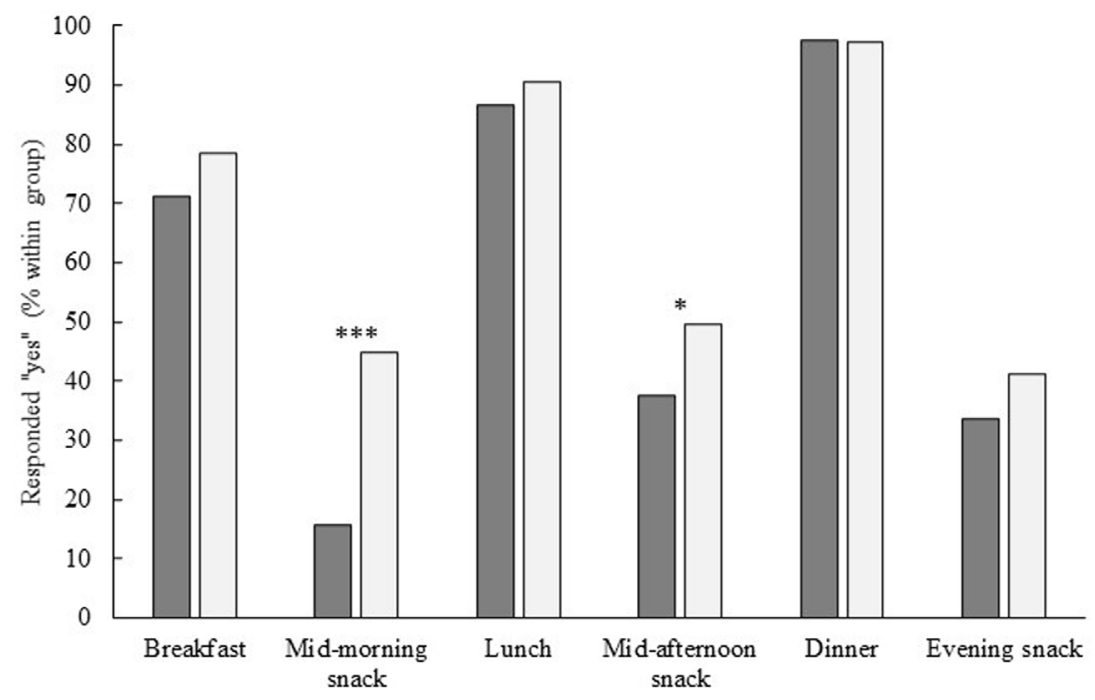

B.

Fasting-day meal and snack patterns

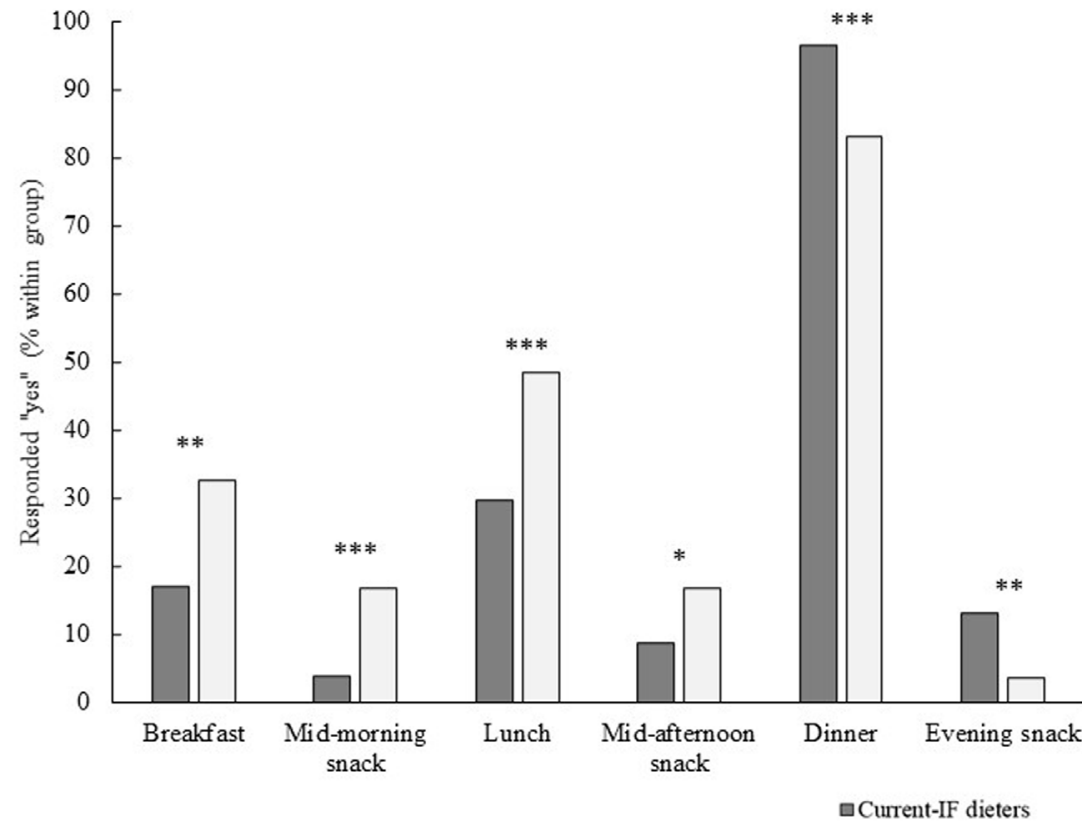

$N=312,{ }^{*} \mathrm{p}<.05,{ }^{*} p<<.01,{ }^{* * *} p<.001$

口Former-IF dieters

Fig. 1. Meal and snack preferences on non-fasting-days (Panel A) and fasting-days (Panel B) reported by Current-IF and Former-IF Dieters. Values are displayed as percentages within each group that responded "yes" to each meal or snack opportunity.

challenge adherence to an IF diet by encouraging a tendency to eat more frequently (to replenish energy stores). Additionally, individuals' previous history of disordered eating was not assessed in this study. Individuals with disordered eating may be more concerned about IF and this may cause lowered adherence to the diet.

The importance of eating breakfast is often promoted by evidence showing an association between eating later in the day (or late at night) and increased BMI (Kinsey \& Ormsbee, 2015). However, this evidence, similar to the previously described relationship between breakfast consumption and performance in school, is not causal and the impact of eating later in the day on BMI is unclear. For some, a potential benefit of consuming consistent meals throughout the day is that it might reduce unplanned snacking behaviour (Berg \& Forslund, 2015). Individuals who snack regularly might be less likely to attempt an IF diet or may be less adherent to the diet because routinely snacking prevents over-eating late at night. We note that adherent (Current-IF) dieters were less likely to report snacking behaviour on both fasting and nonfasting-days.

Many forms of IF have become popular in recent years; however, this way of eating is not revolutionary. Intermittent fasting has formed a significant part of many religious practices for centuries (Dietler, 2011, pp. 179-194) and meal size, frequency and timing are socio- 
culturally determined (De Castro, 1997). Evolutionary biologists suggest that prior to the development of agriculture, humans were primarily hunter-gatherers and would have regularly experienced periods of food scarcity followed by periods of food abundance (Chakravarthy \& Booth, 2004). However, the current eating environment is characterised by continuous food availability, and the overarching recommendation is that adults and children should eat regularly throughout the day to maintain a "healthy" diet. As obesity continues to be a leading contributor to many major health conditions and diseases, the recommendation to eat frequently may no longer be appropriate.

\section{Conclusion}

The present study adds value to the current literature describing factors that promote IF diet adherence by assessing the role of psychological factors (such as beliefs). Previous research has highlighted the lack of available data regarding such psychological factors as a limitation to their key findings (Varady et al., 2016). For many, IF diets seem to require less effort than daily calorie restriction diets, are costeffective, and are a useful tool in promoting weight loss and maintenance (Brown, Mosley, \& Aldred, 2013). However, this study highlights that IF diets may not be effective for everyone, particularly those with strongly held beliefs about the potential negative consequences of missing regular meal and snack times. A potential avenue for future research could be to explore the possibility of modifying these baseline beliefs about hunger and healthy meal patterns in order to promote IF diet adherence.

\section{Funding}

This work was supported by an Engineering and Physical Sciences Research Council PhD studentship awarded to RLG (EP/L504919/1). The Nutrition and Behaviour Unit also receives support from the European Union Seventh Framework Programme (FP7/2007-2013) under Grant Agreement 607310 (Nudge-it). This research was supported by the NIHR Biomedical Research Centre at University Hospitals Bristol NHS Foundation Trust and the University of Bristol. The views expressed in this publication are those of the authors and not necessarily those of the NHS, the National Institute for Health Research or the Department of Health. The funders had no role in the design, analysis or writing of this article.

\section{Conflicts of interest}

None.

\section{Authorship}

CP, RLG, and PJR conceived the study design. CP and RLG created the online survey and conducted the statistical analyses. $\mathrm{CP}$ generated the figures and tables and wrote the manuscript with input and final approval from RLG, JMB, and PJR.

\section{Appendix A. Supplementary data}

Supplementary data to this article can be found online at https:// doi.org/10.1016/j.appet.2018.10.020.

\section{References}

Adolphus, K., Bellissimo, N., Lawton, C. L., Ford, N. A., Rains, T. M., de Zepetnek, J. T., et al. (2017). Methodological challenges in studies examining the effects of breakfast on cognitive performance and appetite in children and adolescents. Advances in Nutrition: An International Review Journal, 8(1), 184S-196S. https://doi.org/10.3945/ an.116.012831.

Assanand, S. (1996). Personal theories of hunger and eating (Doctoral dissertation). https://dx.doi.org/10.14288/1.0087215.
Berg, C., \& Forslund, H. B. (2015). The influence of portion size and timing of meals on weight balance and obesity. Current Obesity Reports, 4(1), 11-18. https://doi.org/10. 1007/s13679-015-0138-y.

BOS (2015). Bristol online survey. Retrieved from https://www.onlinesurveys.ac.uk/.

Brown, J. E., Mosley, M., \& Aldred, S. (2013). Intermittent fasting: A dietary intervention for prevention of diabetes and cardiovascular disease? The British Journal of Diabetes \& Vascular Disease, 13(2), 68-72. https://doi.org/10.1177/1474651413486496.

Brunstrom, J. M., Jarvstad, A., Griggs, R. L., Potter, C., Evans, N. R., Martin, A. A., ... Rogers, P. J. (2016). Large portions encourage the selection of palatable rather than filling foods. Journal of Nutrition, 146(10), 2117-2123. https://doi.org/10.3945/jn. 116.235184.

Brunstrom, J. M., \& Rogers, P. J. (2009). How many calories are on our plate? Expected fullness, not liking, determines meal-size selection. Obesity, 17(10), 1884-1890. https://doi.org/10.1038/oby.2009.201.

Chakravarthy, M. V., \& Booth, F. W. (2004). Eating, exercise, and "thrifty" genotypes: Connecting the dots toward an evolutionary understanding of modern chronic diseases. Journal of Applied Physiology, 96(1), 3-10. https://doi.org/10.1152/ japplphysiol.00757.2003.

Davis, C. S., Clarke, R. E., Coulter, S. N., Rounsefell, K. N., Walker, R. E., Rauch, C. E., .. Ryan, L. (2016). Intermittent energy restriction and weight loss: A systematic review. European Journal of Clinical Nutrition, 70(3), 292-299. https://doi.org/10.1038/ejcn. 2015.195.

De Castro, J. M. (1997). Socio-cultural determinants of meal size and frequency. British Journal of Nutrition, 77(Suppl 1), S39-S54. discussion S54-35 https://doi.org/10. 1079/BJN19970103.

Dickie, N. H., \& Bender, A. E. (1982). Breakfast and performance in schoolchildren. British Journal of Nutrition, 48(03), 483-496. https://doi.org/10.1079/BJN19820134.

Dietler, M. (2011). Feasting and fasting. The Oxford handbook of the archaeology of ritual and religionhttps://doi.org/10.1093/oxfordhb/9780199232444.013.0014.

Faíbry, P., \& Tepperman, J. (1970). Meal frequency-a possible factor in human pathology. American Journal of Clinical Nutrition, 23(8), 1059-1068. https://doi.org/10. 1093/ajen/23.8.1059.

Forslund, H. B., Lindroos, A. K., Sjostrom, L., \& Lissner, L. (2002). Meal patterns and obesity in Swedish women-a simple instrument describing usual meal types, frequency and temporal distribution. European Journal of Clinical Nutrition, 56(8), 740-747. https://doi.org/10.1038/sj.ejcn.1601387.

Forslund, H. B., Torgerson, J. S., Sjöström, L., \& Lindroos, A. K. (2005). Snacking frequency in relation to energy intake and food choices in obese men and women compared to a reference population. International Journal of Obesity, 29(6), 711-719. https://doi.org/10.1038/sj.ijo.0802950.

Heilbronn, L. K., Smith, S. R., Martin, C. K., Anton, S. D., \& Ravussin, E. (2005). Alternateday fasting in nonobese subjects: Effects on body weight, body composition, and energy metabolism. American Journal of Clinical Nutrition, 81(1), 69-73. https://doi. org/10.1093/ajen/81.1.69.

Kinsey, A. W., \& Ormsbee, M. J. (2015). The health impact of nighttime eating: Old and new perspectives. Nutrients, 7(4), 2648-2662. https://doi.org/10.3390/nu7042648.

Lloyd, H. M., Rogers, P. J., Hedderley, D. I., \& Walker, A. F. (1996). Acute effects on mood and cognitive performance of breakfasts differing in fat and carbohydrate content. Appetite, 27(2), 151-164. https://doi.org/10.1006/appe.1996.0042.

Ma, Y., Bertone, E. R., Stanek, E. J., 3rd, Reed, G. W., Hebert, J. R., Cohen, N. L., ... Ockene, I. S. (2003). Association between eating patterns and obesity in a free-living US adult population. American Journal of Epidemiology, 158(1), 85-92. https://doi. org/10.1093/aje/kwg117.

Mahoney, C. R., Taylor, H. A., Kanarek, R. B., \& Samuel, P. (2005). Effect of breakfast composition on cognitive processes in elementary school children. Physiology \& Behavior, 85(5), 635-645. https://doi.org/10.1016/j.physbeh.2005.06.023.

Mosley, M., \& Spencer, M. (2015). The FastDiet-revised \& updated: Lose weight, stay healthy, and live longer with the simple secret of intermittent fasting. Simon and Schuster.

NHS (2015a). Eight tips for healthy eating. Retrieved from http://www.nhs.uk/Livewell/ Goodfood/Pages/eight-tips-healthy-eating.aspx\# breakfast.

NHS (2015b). Healthy breakfasts (for people who hate breakfast). Retrieved from http:// www.nhs.uk/livewell/loseweight/pages/healthybreakfasts.aspx.

Rampersaud, G. C., Pereira, M. A., Girard, B. L., Adams, J., \& Metzl, J. D. (2005). Breakfast habits, nutritional status, body weight, and academic performance in children and adolescents. Journal of the American Dietetic Association, 105(5), 743-760. https://doi.org/10.1016/j.jada.2005.02.007.

Rogers, P. J. (1997). How important is breakfast? British Journal of Nutrition, 78(02), 197-198. https://doi.org/10.1079/BJN19970139.

Rogers, P. J., \& Brunstrom, J. M. (2016). Appetite and energy balancing. Physiology \& Behavior, 164(Pt B), 465-471. https://doi.org/10.1016/j.physbeh.2016.03.038.

Rogers, P. J., Ferriday, D., Jebb, S. A., \& Brunstrom, J. M. (2016). Connecting biology with psychology to make sense of appetite control. Nutrition Bulletin, 41(4), 344-352. https://doi.org/10.1111/nbu.12237.

Rogers, P. J., Ferriday, D., Smith, J. E., Duxbury, S., Richards, S., \& Brunstrom, J. M. (2013). E.25 - inverse dose-response effect of breakfast on psychomotor performance. Behavioural Pharmacology, 24, e48. https://doi.org/10.1097/01.fbp.0000434844. 38752.73.

Sclafani, A., \& Ackroff, K. (2004). The relationship between food reward and satiation revisited. Physiology \& Behavior, 82(1), 89-95. https://doi.org/10.1016/j.physbeh. 2004.04.045.

Seimon, R. V., Roekenes, J. A., Zibellini, J., Zhu, B., Gibson, A. A., Hills, A. P., ... Sainsbury, A. (2015). Do intermittent diets provide physiological benefits over continuous diets for weight loss? A systematic review of clinical trials. Molecular and Cellular Endocrinology, 418, 153-172. https://doi.org/10.1016/j.mce.2015.09.014.

Toschke, A. M., Küchenhoff, H., Koletzko, B., \& Kries, R. (2005). Meal frequency and childhood obesity. Obesity Research, 13(11), 1932-1938. https://doi.org/10.1038/ 
oby. 2005.238 .

Toschke, A. M., Thorsteinsdottir, K. H., \& von Kries, R. (2009). Meal frequency, breakfast consumption and childhood obesity. International Journal of Pediatric Obesity, 4(4), 242-248. https://doi.org/10.3109/17477160902763341.

Varady, K. A. (2011). Intermittent versus daily calorie restriction: Which diet regimen is more effective for weight loss? Obesity Reviews, 12(7), e593-601. https://doi.org/10. 1111/j.1467-789X.2011.00873.x.

Varady, K. A., \& Gottlieb, B. (2013). The every-other-day diet: The diet that lets you eat all you want (half the time) and keep the weight off. Hachette Books.

Varady, K. A., \& Hellerstein, M. K. (2007). Alternate-day fasting and chronic disease prevention: A review of human and animal trials. American Journal of Clinical Nutrition, 86(1), 7-13. https://doi.org/10.1093/ajcn/86.1.7.
Varady, K. A., Hoddy, K. K., Kroeger, C. M., Trepanowski, J. F., Klempel, M. C., Barnosky, A., et al. (2016). Determinants of weight loss success with alternate day fasting. Obesity Research \& Clinical Practice, 10(4), 476-480. https://doi.org/10.1016/j.orcp. 2015.08.020

Walker, A. R., Walker, B. F., Jones, J., \& Ncongwane, J. (1982). Breakfast habits of adolescents in for South African populations. American Journal of Clinical Nutrition, 36(4), 650-656. https://doi.org/10.1093/ajcn/36.4.650.

Yoshimura, E., Hatamoto, Y., Yonekura, S., \& Tanaka, H. (2017). Skipping breakfast reduces energy intake and physical activity in healthy women who are habitual breakfast eaters: A randomized crossover trial. Physiology \& Behavior, 174, 89-94. https://doi.org/10.1016/j.physbeh.2017.03.008. 